\title{
SYZYGIUM CUMINI (L.) SKEELS LEAF EXTRACT FRACTIONS AS ARGINASE INHIBITORS AND THE EFFECTS OF TANNINS ON THEIR ACTIVITY
}

\author{
ARI ARIEFAH HIDAYATI ${ }^{1}$, BERNA ELYA ${ }^{2 *}$, RANI SAURIASARI ${ }^{3}$ \\ ${ }^{1}$ Graduate Program, Faculty of Pharmacy, Universitas Indonesia. ${ }^{2}$ Departement of Pharmacognosy-Pythochemistry, Faculty of Pharmacy, \\ Universitas Indonesia, Depok, Jawa Barat 16424, Indonesia. ${ }^{3}$ Departement of Clinical Pharmacy, Faculty of Pharmacy, Universitas \\ Indonesia, Depok, Jawa Barat 16424, Indonesia. Email: berna.elya@farmasi.ui.ac.id
}

Received: 30 September 2019, Revised and Accepted: 23 December 2019

ABSTRACT

Objective: Arginase inhibition could be a potential therapeutic approach for endothelial dysfunction. Syzygium cumini (L.) Skeels leaves contain phenolic acids and flavonoids, which have been predicted to exhibit arginase inhibitory activity. Moreover, these leaves contain tannins, which can form complexes with enzymes and lead to false-positive results during biological testing. Therefore, this study was conducted to evaluate the arginase inhibitory activity of $S$. cumini leaf extract and fractions as well as to elucidate the effects of tannins on this activity.

Methods: S. cumini leaves were fractionated using n-hexane, ethyl acetate, and methanol. A colorimetric method was employed to evaluate arginase inhibitory activity. Tannin elimination was performed through the gelatin precipitation method. Total phenolic and flavonoid contents of the fractions were calculated using the Folin-Ciocalteu and aluminum chloride methods, respectively.

Results: Ethyl acetate and methanol fractions showed arginase inhibitory activity with half-maximal inhibitory concentrations (IC ${ }_{50}$ ) of 46.96 and $15.35 \mu \mathrm{g} / \mathrm{mL}$, respectively. The methanol fraction was positive for tannins. After tannin elimination, this fraction exhibited less potent arginase inhibitory activity, with an $\mathrm{IC}_{50}$ value of $53.03 \mu \mathrm{g} / \mathrm{mL}$. The ethyl acetate fraction showed higher total phenolic and flavonoid contents than the methanol fraction.

Conclusion: Tannins affected the arginase inhibitory activity of the methanol fraction of S. cumini leaves; however, the ethyl acetate fraction did not contain tannins and could inhibit arginase activity.

Keywords: Arginase inhibitor, Ethyl acetate fraction, Methanol fraction, Syzygium cumini, Tannins.

(c) 2020 The Authors. Published by Innovare Academic Sciences Pvt Ltd. This is an open access article under the CC BY license (http://creativecommons. org/licenses/by/4. 0/) DOI: http://dx.doi.org/10.22159/ijap.2020.v12s1.FF059

\section{INTRODUCTION}

The endothelium plays an important role as the central hub for vascular structure, tone, and homeostasis regulation in cardiovascular physiology. Endothelial dysfunction could serve as a predictor of various vascular diseases that lead to pathological conditions. Endothelial dysfunction is characterized by depleted levels of nitric oxide (NO) - a potent vasodilator biomarker [1].

NO synthesis is catalyzed by endothelial NO synthase (eNOS) from the amino acid L-arginine with cofactor tetrahydrobiopterin (BH4) [2]. L-arginine is also utilized by arginase as a substrate to produce L-ornithine and urea. Competition between eNOS and arginase may occur under pathophysiological conditions. Thus, increased expression and/or activity of arginase in endothelial cells can disrupt NO synthesis [3].

When L-arginine levels decrease due to arginase activity, eNOS may become unstable and uncoupled. Hence, decreased NO production can result in the generation of more superoxide radicals. Superoxide can react with $\mathrm{NO}$ to form peroxynitrite, which can oxidize BH4 and cause eNOS uncoupling, thus down regulating NO production [2]. Furthermore, reactive nitrogen and oxygen species may oxidize iron in the Hem Group $\left(\mathrm{Fe}^{2+}\right.$ to $\left.\mathrm{Fe}^{3+}\right)$ located within soluble guanylyl cyclase (sGC). This oxidation makes sGC unresponsive to $\mathrm{NO}$ and vasodilatation is blocked [4]. Therefore, arginase inhibition and oxidation prevention may be considered as potential therapeutic approaches for endothelial dysfunction $[1,2]$.

Studies have shown arginase inhibitory activities of plant substances or extracts. Some examples include Theobroma cacao flavonol mixture,
Caesalpinia sappan heartwood ethyl acetate extract, Korean red ginseng root extract, Scutellaria indica flavanones, and hydroalcoholic extract from Melastoma malabathricum leaves [5-9]. Some natural compounds have also been reported to show arginase inhibitory activity in vitro, such as chlorogenic acid, piceatannol, resveratrol, (-)-epicatechin, taxifolin, quercetin, and caffeic acid [10].

Syzygium cumini (L.) Skeels hydroethanolic leaf extract possesses pharmacological activities that impact vascular diseases such as antihypertensive effects, antihyperglycemic activity, and antioxidant properties [11,12]. Various phytoconstituents such as phenolic acids, tannins, flavonoids, and terpenes have already been identified in this extract [13-16]. Phenolic acids and flavonoids of S. cumini are hypothesized to exhibit arginase inhibitory activity. However, tannins could serve as inhibitors of enzymatic activity through the formation of complexes with enzymes, resulting in false-positive results during biological testing [17]. Therefore, this study was conducted to evaluate the arginase inhibitory activity of the S. cumini leaf fractions and to elucidate the effects of tannins on this activity.

\section{METHODS}

\section{Chemicals}

Bovine liver arginase, L-arginine, maleic acid, mangan sulfate, gallic acid, resveratrol, aluminum chloride, and iron (III) chloride were purchased from Sigma-Aldrich (Singapore). The Urea Assay Kit was purchased from Abnova (Taiwan). Dimethyl sulfoxide, Folin-Ciocalteu reagent, methanol, ethyl acetate, n-hexane, and other solvents were of analytical grade and obtained from Merck (Germany). 


\section{Sample preparation}

S. cumini leaves were collected from Bogor Botanical Garden, Indonesia, and positively identified by Indonesia Science Institution. After harvesting, leaves were cleaned and air-dried. Dried leaves were pulverized and extracted using 70\% ethanol through maceration at room temperature [11]. The filtrate concentrated using a rotary vacuum evaporator and then vacuum-dried. Dried extract was dispersed in aquadest and fractionated by liquid-liquid partition using $\mathrm{n}$-hexane and ethyl acetate until the solvent became colorless; this was then evaporated under vacuum conditions to obtain the n-hexane and ethyl acetate fractions [18]. Thereafter, the aqueous residue was further evaporated and vacuum-dried. Dried aqueous residue was dissolved in methanol; when the methanol phase became intensely colored, it was separated from the solid phase. Methanol fractionation was repeated until the methanol phase became colorless and the methanol filtrate was collected and evaporated to obtain the methanol fraction.

\section{Tannin elimination}

First, the n-hexane, ethyl acetate, and methanol fractions were screened for tannins using a gelatin test and iron (III) chloride. The methanol fraction was positive for tannins and tannin elimination was then performed through the gelatin precipitation method [19]. A gelatin solution was added to the methanol fraction to precipitate tannins. The solution was centrifuged at $100 \mathrm{rpm}$ for $15 \mathrm{~min}$ to separate the precipitate. Supernatant was collected to test its arginase inhibitory activity following tannin elimination.

\section{Arginase inhibitory activity assay}

Enzyme inhibition activity was determined using arginase enzymatic assay (Sigma-Aldrich, Singapore) and urea determination assay kits (Abnova Corporation, Taiwan), as described elsewhere [9]. The test $(10 \mu \mathrm{L})$, arginase $1 \mathrm{U} / \mathrm{mL}(15 \mu \mathrm{L})$, and L-arginine $380 \mathrm{mM}(20 \mu \mathrm{L})$ solutions were mixed in 96 -well microplates and incubated at $37^{\circ} \mathrm{C}$ for $30 \mathrm{~min}$. Test solution was substituted by dimethyl sulfoxide solution in control wells. For blank wells, an arginase solution was added following the first incubation. Then, $100 \mu \mathrm{L}$ of reagent mixture from the Urea Assay Kit (reagents A: B, 1:1) was added to each well. Absorbance was measured using a microplate reader (Versamax, USA) after a second incubation at $25^{\circ} \mathrm{C}$ for $60 \mathrm{~min}$. Resveratrol was used as the positive standard, which was tested at a concentration range of 8.76-43.81 $\mu \mathrm{M}$. Absorbance was measured at $430 \mathrm{~nm}$. Percent inhibition was calculated using the following formula:

$$
\text { Inhibition }(\%)=\frac{\left(A_{c}-A_{c b}\right)-\left(A_{s}-A_{s b}\right)}{\left(A_{c}-A_{c b}\right)} \times 100
$$

where $A_{c}$ is absorbance of the control, $A_{c b}$ is absorbance of the control blank, $A_{s}$ is absorbance of the test sample, and $A_{s b}$ is absorbance of the blank of test sample.

\section{Total phenolic content determination}

Total phenolic content of the active fractions that inhibited arginase was determined using the Folin-Ciocalteu method [9]. In a 96-well microplate, $100 \mu \mathrm{L}$ of diluted Folin-Ciocalteu reagent (1:4) was added to $25 \mu \mathrm{L}$ of either a fraction or standard solution. The mixture was homogenized by shaking for $1 \mathrm{~min}$ and left to stand for $4 \mathrm{~min}$. Next, $75 \mu \mathrm{L}$ of $\mathrm{Na}_{2} \mathrm{CO}_{3}$ solution $(100 \mathrm{~g} / \mathrm{L})$ was added to each well followed by homogenization by shaking for $1 \mathrm{~min}$. After incubation for $2 \mathrm{~h}$ at room temperature in the dark, absorbance was measured at $750 \mathrm{~nm}$ using the microplate reader. Gallic acid was used as a standard to quantify phenolic content; the calibration curve was prepared using gallic acid at a concentration of $25-150 \mu \mathrm{g} / \mathrm{mL}$. Total phenolic content of the fractions was expressed as gallic acid equivalents (i.e., mg of gallic acid equivalents per $\mathrm{g}$ of fraction).

\section{Total flavonoid content determination}

Determination of total flavonoid content of the active fractions was performed using the aluminum chloride method, as previously described with slight modifications [20]. Briefly, $0.5 \mathrm{~mL}$ of the fraction or standard solution was sequentially added to $1.5 \mathrm{~mL}$ of ethanol, $0.1 \mathrm{~mL}$ of $\mathrm{AlCl}_{3}$ solution (10\%), $0.1 \mathrm{~mL}$ of sodium acetate solution (1 M), and $2.8 \mathrm{~mL}$ distilled water. The mixture was homogenized by vortexing for 1 min. For the sample blank, the $\mathrm{AlCl}_{3}$ solution was substituted by distilled water of the same quantity. After $30 \mathrm{~min}$ of incubation at room temperature, absorbance was measured at $430 \mathrm{~nm}$ using a ultraviolet-visible spectrophotometer (Shimadzu 265, Japan). The calibration curve was prepared using quercetin at a concentration of $30-80 \mu \mathrm{g} / \mathrm{mL}$. Total flavonoid content of the fractions was expressed as quercetin equivalents (i.e., $\mathrm{mg}$ of quercetin equivalents per $\mathrm{g}$ of fraction).

\section{RESULTS}

\section{Arginase inhibitory activity}

Resveratrol was used as positive control and showed arginase inhibitory activity with half-maximal inhibitory concentration $\left(\mathrm{IC}_{50}\right)$ value $17.56 \mu \mathrm{M}$. The $\mathrm{n}$-Hexane, ethyl acetate, and methanol fractions of $S$. cumini leaves were evaluated for arginase inhibitory activity. At $100 \mu \mathrm{g} / \mathrm{mL}$, the n-hexane and ethyl acetate fractions inhibited arginase at $20.90 \%$ and $89.74 \%$, respectively. At $30 \mu \mathrm{g} / \mathrm{mL}$, the methanol fraction inhibited arginase at $89.21 \%$. In this study, the fraction was considered to have in vitro arginase inhibitory activity if enzyme activity was inhibited by $>50 \%$ at concentrations $<100 \mu \mathrm{g} / \mathrm{mL}$. Because the n-hexane fraction did not obtain $50 \%$ inhibition, this fraction was not considered to be an active arginase inhibitor and further $\mathrm{IC}_{50}$ determination was not conducted. $\mathrm{IC}_{50}$ values for the ethyl acetate and methanol fractions are presented in Table 1 .

\section{Total phenolic content determination}

The total phenolic content of the active fraction was calculated using a gallic acid calibration curve using the equation $y=0.0062 x+0.0502$. The total phenolic contents of the ethyl acetate and methanol fractions are presented in Table 2. The ethyl acetate fraction of $S$. cumini leaves showed higher phenolic content than the methanol fraction.

\section{Total flavonoid content determination}

The total phenolic content of the active fraction was calculated using a quercetin calibration curve with the equation $y=0.0086 \mathrm{x}-0.0229$. The total flavonoid content of the ethyl acetate and methanol fractions is presented in Table 2. The ethyl acetate fraction exhibited higher flavonoid content than the methanol fraction.

\section{DISCUSSION}

In this study, arginase inhibitory activity was evaluated in vitro using an indirect technique through urea measurement as urea is a product of an L-arginine and arginase reaction [3]. Resveratrol was used as a positive control base on previous data by Bordage et al. who showed that

Table 1: Arginase inhibitory activity of active fractions derived from Syzygium cumini leaves presented as IC $_{50}$

\begin{tabular}{lll}
\hline Sample & $\begin{array}{l}\text { Linear regression } \\
\text { equation }\end{array}$ & IC $_{\mathbf{5 0}}(\boldsymbol{\mu g} / \mathbf{m L})$ \\
\hline Ethyl acetate fraction & $\mathrm{y}=0.702 \mathrm{x}+17.011$ & 46.96 \\
Methanol fraction & $\mathrm{y}=2.855 \mathrm{x}+6.163$ & 15.35 \\
Methanol fraction after & $\mathrm{y}=0.641 \mathrm{x}+16.026$ & 53.03 \\
tannin elimination & & \\
\hline
\end{tabular}

$\mathrm{IC}_{50}$ : Half-maximal inhibitory concentration

Table 2: Phytoconstituents content Syzygium cumini leaf fractions

\begin{tabular}{lll}
\hline Sample fraction & $\begin{array}{l}\text { Total phenolic } \\
\text { content (mg GAE/g) }\end{array}$ & $\begin{array}{l}\text { Total flavonoid } \\
\text { content (mg QE/g) }\end{array}$ \\
\hline Ethyl acetate & $645.16 \pm 12.18$ & $25.22 \pm 2.13$ \\
Methanol & $532.93 \pm 7.27$ & $8.08 \pm 0.51$ \\
\hline
\end{tabular}




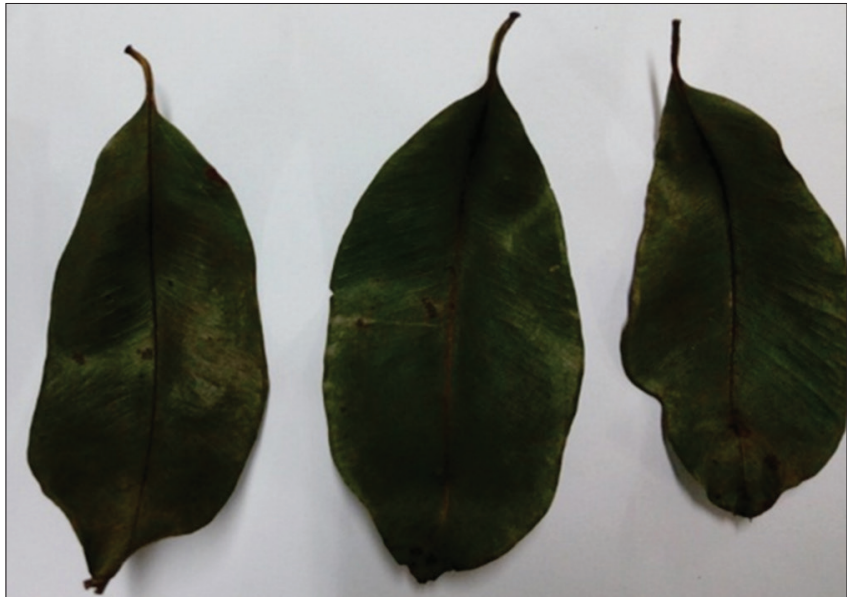

Fig. 1: Syzygium cumini (L.) Skeels leaves

resveratrol inhibited arginase activity in vitro, with a $\mathrm{IC}_{50}$ of $18.2 \mu \mathrm{M}$ [10]. The $\mathrm{IC}_{50}$ value obtained in this study was slightly different; this difference may be caused by different assay methods or conditions employed.

As investigated in previous studies, S. cumini leaves (Fig. 1) possess pharmacological activities [11,12]. Arginase inhibitory activity of the fractions of $S$. cumini leaves was evaluated. The methanol fraction exhibited a lower $\mathrm{IC}_{50}$ value than the ethyl acetate fraction, indicating higher arginase inhibition potency. However, after screening for tannins through gelatin test and iron (III) chloride, the n-hexane and ethyl acetate fractions contained no tannins, while the methanol fraction tested positive. Tannins within the methanol fraction were eliminated. Following tannin elimination, this fraction exhibited arginase inhibitory activity, but it was weaker than that of the crude methanol fraction. This finding indicates the tannins affect arginase inhibition. Tannins may form precipitates with protein, including enzymes, through binding and aggregation [17].

Some phytoconstituents in $S$. cumini leaves such as quercetin, kaempferol, catechin, gallic acid, caffeic acid, and chlorogenic acid have been reported to show arginase inhibitory activity [10,13,14,21-23]. At $1 \mathrm{mM}$, gallic acid and catechin exhibited arginase inhibitory activity at $20 \%$ and $26 \%$, respectively [23]. Kaempferol, caffeic acid, quercetin, and chlorogenic acid showed arginase inhibition with $\mathrm{IC}_{50}$ values of $179.1,86.7,31.2$, and $10.6 \mu \mathrm{M}$, respectively [10].

The phenolic and flavonoid compounds contained within S. cumini leaves might be responsible for their arginase inhibitory activity. The ethyl acetate fraction showed higher phenolic and flavonoid contents than the methanol fraction. The ethyl acetate fraction also showed an $\mathrm{IC}_{50}$ value lower than that of the methanol fraction following tannin elimination, indicating a higher potency for arginase inhibition.

\section{CONCLUSION}

This study demonstrated that tannins could contribute to arginase inhibitory activity. The ethyl acetate fraction of $S$. cumini leaves did not contain tannins and might be considered as having the most inhibitory potential among all the fractions.

\section{CONFLICTS OF INTEREST}

All authors have none to declare.

\section{REFERENCES}

1. Steppan J, Nyhan D, Berkowitz DE. Development of novel arginase inhibitors for therapy of endothelial dysfunction. Front Immunol $2013 ; 4: 278$

2. Kietadisorn R, Juni RP, Moens AL. Tackling endothelial dysfunction by modulating NOS uncoupling: New insights into its pathogenesis and therapeutic possibilities. Am J Physiol Endocrinol Metab 2012;302:E481-95.

3. Pudlo M, Demougeot C, Girard-Thernier C. Arginase inhibitors: A rational approach over one century. Med Res Rev 2017;37:475-513.

4. Lundberg JO, Gladwin MT, Weitzberg E. Strategies to increase nitric oxide signalling in cardiovascular disease. Nat Rev Drug Discov 2015; 14:623-41.

5. Schnorr O, Brossette T, Momma TY, Kleinbongard P, Keen CL, Schroeter $\mathrm{H}$, et al. Cocoa flavanols lower vascular arginase activity in human endothelial cells in vitro and in erythrocytes in vivo. Arch Biochem Biophys 2008;476:211-5.

6. Shin W, Cuong TD, Lee JH, Min B, Jeon BH, Lim HK, et al. Arginase inhibition by ethylacetate extract of Caesalpinia sappan lignum contributes to activation of endothelial nitric oxide synthase. Korean J Physiol Pharmacol 2011;15:123-8.

7. Shin W, Yoon J, Oh GT, Ryoo S. Korean red ginseng inhibits arginase and contributes to endotheliumdependent vasorelaxation through endothelial nitric oxide synthase coupling. J Ginseng Res 2013;37:64-73.

8. Kim SW, Cuong TD, Hung TM, Ryoo S, Lee JH, Min BS. Arginase II inhibitory activity of flavonoid compounds from Scutellaria indica. Arch Pharm Res 2013;36:922-6.

9. Sembiring EN, Elya B, Sauriasari R. Inhibitory effect on arginase and total phenolic content determination of extracts from different parts of Melastoma malabathricum L. J Young Pharm 2018;10:s114-7.

10. Bordage S, Pham TN, Zedet A, Gugglielmetti AS, Nappey M, Demougeot $\mathrm{C}$, et al. Investigation of mammal arginase inhibitory properties of natural ubiquitous polyphenols by using an optimized colorimetric microplate assay. Planta Med 2017;83:647-53.

11. Ribeiro RM, Pinheiro Neto VF, Ribeiro KS, Vieira DA, Abreu IC, Silva Sdo N, et al. Antihypertensive effect of Syzygium cumini in spontaneously hypertensive Rats. Evid Based Complement Alternat Med 2014:2014:605452.

12. Sanches JR, França LM, Chagas VT, Gaspar RS, Dos Santos KA, Gonçalves LM, et al. Polyphenol-rich extract of Syzygium cumini leaf dually improves peripheral insulin sensitivity and pancreatic islet function in monosodium L-glutamate-induced obese rats. Front Pharmacol 2016;7:48.

13. Mahmoud II, Marzouk MS, Moharram FA, El-Gindi MR, Hassan AM. Acylated flavonol glycosides from Eugenia jambolana leaves. Phytochemistry 2001;58:1239-44.

14. Ruan ZP, Zhang LL, Lin YM. Evaluation of the antioxidant activity of Syzygium cumini leaves. Molecules 2008;13:2545-56.

15. De Bona KS, Bellé LP, Sari MH, Schetinger MR, Morsch VM, Boligon A, et al. Syzygium cumini extract decrease adenosine deaminase, 5 ' nucleotidase activities and oxidative damage in platelets of diabetic patients. Cell Physiol Biochem 2010;26:729-38.

16. Chagas VT, França LM, Malik S, Paes AM. Syzygium cumini (L.) skeels: A prominent source of bioactive molecules against cardiometabolic diseases. Front Pharmacol 2015;6:259.

17. Adamczyk B, Simon J, Kitunen V, Adamczyk S, Smolander A. Tannins and their complex interaction with different organic nitrogen compounds and enzymes: Old paradigms versus recent advances. ChemistryOpen 2017;6:610-4.

18. Mustarichie R, Runadi D, Ramdhani D. The Antioxidant activity and phytochemical screening of ethanol extract, fractions of water, ethyl acetate, and n-hexane from mistletoe tea (Scurrula atropurpurea Bl. Dans). Asian J Pharm Clin Res 2017;10:343-7.

19. Prommajak T, Leksawasdi N, Rattanapanone N. Optimizing tannin precipitation in cashew apple juice. CMU J Nat Sci 2018;17:14-23.

20. Nithya A, Jayanthi J, Ragunathan MG. Antioxidant activity, total phenol, flavonoid, alkaloid, tannin, and saponin contents of leaf extracts of Salvinia molesta D. S. Mitchell. Asian J Pharm Clin Res 2016;9:200-3.

21. Timbola AK, Szpoganicz B, Branco A, Monache FD, Pizzolatti MG. A new flavonol from leaves of Eugenia jambolana. Fitoterapia 2002;73:174-6.

22. Ecker A, Araujo Vieira F, de Souza Prestes A, Mulling Dos Santos M, Ramos A, Dias Ferreira R, et al. Effect of Syzygium cumini and Bauhinia forficata aqueous-leaf extracts on oxidative and mitochondrial parameters in vitro. EXCLI J 2015;14:1219-31.

23. dos Reis MB, Manjolin LC, Maquiaveli Cdo C, Santos-Filho OA, da Silva ER. Inhibition of Leishmania (Leishmania) amazonensis and rat arginases by green tea EGCG, (+)-catechin and (-)-epicatechin: A comparative structural analysis of enzyme-inhibitor interactions. PLoS One 2013;8:e78387. 